\title{
ANÁLISE DOS FATORES HUMANOS E CONDIÇÕES DE TRABALHO NO PROCESSAMENTO MECÂNICO PRIMÁRIO E SECUNDÁRIO DA MADEIRA ${ }^{1}$
}

\section{ANALYSIS OF HUMAN FACTORS AND WORK CONDITIONS IN TIMBER PRIMARY AND SECONDARY MECHANICAL PROCESSING}

\author{
Eduardo da Silva Lopes ${ }^{2}$ Erinton Zanlorenzi ${ }^{3}$ Luiz Carlos Couto ${ }^{2}$
}

\section{RESUMO}

Esta pesquisa teve como objetivo analisar os fatores humanos e as condições de trabalho dos funcionários que atuavam nas indústrias de processamento de madeira localizadas na região centro-sul do estado do Paraná, visando à melhoria da saúde, do bem-estar, da segurança, do conforto e da produtividade dos trabalhadores. Os dados foram coletados por meio de entrevistas individuais e medições dos trabalhadores. Os resultados demonstraram que os trabalhadores que atuam nas indústrias de processamento de madeira apresentaram um perfil de pessoa jovem, de origem urbana, casados, com poucos filhos e possuidores de casa própria. Os resultados ainda indicaram que o tempo médio dos trabalhadores na empresa era relativamente longo (75,5 meses), enquanto o tempo na função foi de 40,7 meses. O percentual de consumidores de cigarros e de bebidas alcoólicas foi significativo. As maiores reclamações sobre dores no corpo foram relativas as lombalgias, em razão ao levantamento de excesso de peso e a adoção de posturas inadequadas. O percentual de acidentes de trabalho foi considerado elevado com 43,3\%.

Palavras-chave: fatores humanos, condições de trabalho e ergonomia.

\section{ABSTRACT}

The objective of this research was to analyze the human factors and the work conditions of the workers in various activities involved in the timber process industry, located in central-south of the Parana State, Brazil, aiming to improving health, wellbeing, safety, comfort and productivity. Data were collected through individual interviews and mensurations. The workers involved in timber process industry presented a profile of young men, of urban origin, married, with few children and house owner. The results also indicated that the workers time in the company was relatively long (75.5 months), while the time in the function was of 40.7 months. The percentage of cigarette and alcohol consumers was high. Most complaints about body pain were related to backaches, due to rising of weight excess and adoption of inadequate postures. The percentage of accidents was high.

Key words: human factors, work conditions and ergonomics.

\section{INTRODUÇÃO}

Para caracterizar a mão-de-obra e as condições gerais de trabalho na empresa é necessário conhecer os fatores humanos de seus trabalhadores, assim como a opinião deles a respeito do trabalho, das condições de saúde, alimentação, treinamento e segurança (Fiedler, 1998).

O estudo dos fatores humanos consiste em um levantamento do trabalhador na empresa, analisandose variáveis como: tempo na empresa, tempo na função, estado civil, número de filhos, idade, escolaridade, origem, religiosidade, variáveis antropométricas, etc, enquanto as condições gerais de trabalho na empresa são fatores que influenciam diretamente a satisfação do trabalhador, a produtividade e a manutenção do sistema ser humano-máquina em funcionamento (Minetti, 1996).

Segundo Alves et al. (2002), o conhecimento desses fatores é de fundamental importância para que a área de trabalho, o seu arranjo, as máquinas, os equipamentos e as ferramentas sejam bem adaptados às capacidades psicofisiológicas, antropométricas e biomecânicas do ser humano.

1. Pesquisa apoiada pelo Serviço Social Autônomo Paraná Tecnologia.

2. Professor Adjunto do Departamento de Engenharia Florestal, Universidade Estadual do Centro-Oeste, Caixa Postal 21, CEP 84.500-000, Irati (PR). eslopes@irati.unicentro.br - luizcouto@,irati.unicentro.br

3. Bolsista de Iniciação Científica do Departamento de Engenharia Florestal, Universidade Estadual do Centro-Oeste, Caixa Postal 21, CEP 84.500-000, Irati (PR). zanlorenzi.ez@bol.com.br

Recebido para publicação em 31/03/2003 e aceito em 23/10/2003. 
O desenvolvimento de pesquisas relativas aos fatores humanos e às condições gerais de trabalho, saúde, alimentação, treinamento e segurança dos trabalhadores, bem como as condições ergonômicas das máquinas utilizadas nas empresas é extremamente útil na implementação de novos métodos e técnicas adequadas do ponto de vista técnico e social, melhorias das condições atuais de trabalho, bem como na melhoria dos índices de satisfação do trabalhador, levando ao aumento da produtividade e qualidade do trabalho (Grandjean, 1982; Iida, 1990 e Minetti, 1996).

Esta pesquisa teve como objetivo analisar os fatores humanos e as condições de trabalho dos funcionários envolvidos nas diversas atividades de processamento mecânico primário e secundário da madeira em indústrias na região centro-sul do estado do Paraná.

\section{MATERIAL E MÉTODO}

\section{Área de estudo}

Esta pesquisa foi desenvolvida com dados levantados em três indústrias de processamento de madeira, localizadas nos municípios de Irati, Rebouças e Teixeira Soares, região centro-sul do estado do Paraná, nos meses de junho a julho de 2002. As indústrias processavam madeira visando à fabricação de móveis para atendimento ao mercado interno e exportação. A Figura 1 mostra a seqüência de atividades nos diferentes setores das indústrias de processamento de madeira estudadas.

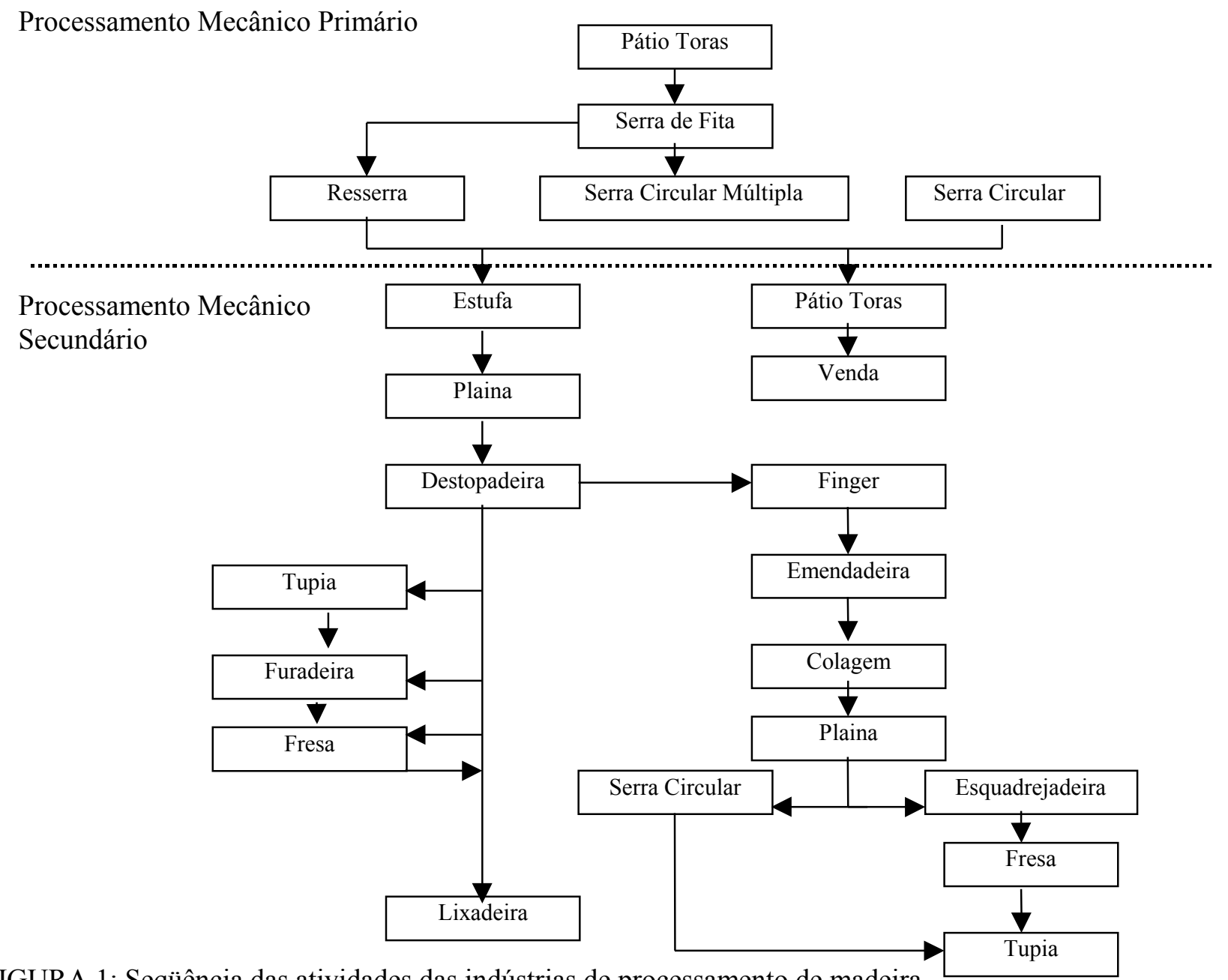

FIGURA 1: Seqüência das atividades das indústrias de processamento de madeira.

FIGURE 1: Timber process industry activity sequence.

\section{População e amostragem}

A população pesquisada era composta por uma amostra de 67 trabalhadores, cobrindo $100 \%$ dos 
trabalhadores que atuavam nas diversas atividades dos setores de processamento mecânico primário e secundário da madeira.

\section{Análise dos fatores humanos e condições gerais de trabalho}

O levantamento dos fatores humanos e condições gerais de trabalho foi realizado por intermédio de um questionário, aplicado aos trabalhadores em forma de entrevista individual, no próprio ambiente de trabalho. As entrevistas permitiram conhecer os fatores humanos, analisando variáveis como idade, estado civil, vícios, escolaridade, origem, tempo na empresa, experiência na atividade, etc. Foram ainda analisadas as condições gerais de trabalho na empresa, envolvendo diversos aspectos relacionados à saúde, alimentação, treinamento e segurança no trabalho.

\section{Opinião dos operadores a respeito das máquinas}

A análise ergonômica das máquinas utilizadas nas indústrias foi realizada mediante um questionário individual aplicado aos trabalhadores em forma de entrevista, de forma a obter subjetivamente, a opinião deles a respeito dos seguintes problemas ergonômicos: segurança; posto de trabalho; vibração e exaustão de gases, poeiras e fuligens.

\section{RESULTADOS E DISCUSSÃO}

\section{Fatores humanos}

$\mathrm{Na}$ Tabela 1, estão os valores das variáveis relativas aos fatores humanos dos trabalhadores envolvidos nas atividades das indústrias de processamento de madeira estudadas.

TABELA 1: Características dos fatores humanos relacionados às atividades das indústrias de processamento de madeira.

TABLES 1: Human factor characteristics related to the timber process industry.

\begin{tabular}{|c|c|c|}
\hline \multicolumn{2}{|c|}{ Características Analisadas } & Valores Médios \\
\hline \multicolumn{2}{|c|}{ Tempo na indústria (meses) } & 75,5 \\
\hline \multicolumn{2}{|c|}{ Tempo na função (meses) } & 40,7 \\
\hline \multirow{4}{*}{$\begin{array}{c}\text { Estado Civil: } \\
(\%)\end{array}$} & Casados & 68,4 \\
\hline & Solteiros & 15,4 \\
\hline & Divorciados & 3,1 \\
\hline & Outros $^{1}$ & 13,1 \\
\hline \multicolumn{2}{|c|}{ Número de filhos } & 2,0 \\
\hline \multicolumn{2}{|c|}{ Idade (anos) } & 32,4 \\
\hline \multicolumn{2}{|l|}{ Estatura $(\mathrm{cm})$} & 169,0 \\
\hline \multicolumn{2}{|l|}{ Peso $(\mathrm{kg})$} & 67,62 \\
\hline \multirow{4}{*}{$\begin{array}{l}\text { Escolaridade: } \\
\qquad(\%)\end{array}$} & Fundamental: Completo & 29,8 \\
\hline & Incompleto & 60,5 \\
\hline & Completo & 15,4 \\
\hline & Incompleto & 6,0 \\
\hline \multirow{2}{*}{$\begin{array}{l}\text { Origem: } \\
(\%)\end{array}$} & Urbana & 67,3 \\
\hline & Rural & 32,7 \\
\hline \multicolumn{2}{|c|}{ Possuidores casa própria (\%) } & 65,5 \\
\hline \multicolumn{2}{|c|}{ Lateralidade destra (\%) } & 87,4 \\
\hline \multirow{2}{*}{$\begin{array}{l}\text { Vícios: } \\
(\%)\end{array}$} & Bebida Alcoólica & 57,4 \\
\hline & Fumantes & 37,5 \\
\hline \multicolumn{2}{|c|}{ Salário Médio Mensal (R\$) } & 304,87 \\
\hline
\end{tabular}

Em que: 1 = Convivência marital.

Os tempos médios dos trabalhadores na empresa e na função foram de 75,5 e 40,7 meses respectivamente. $\mathrm{O}$ longo tempo de trabalho na empresa mostrou que existe uma baixa rotatividade de funcionários. O menor tempo na função em relação ao tempo na empresa, demonstrou que os trabalhadores exerciam outras funções dentro da empresa, atuando especialmente como auxiliares.

Ciência Florestal, v. 13, n. 2, 2003 
Os resultados encontrados evidenciaram que a maioria dos trabalhadores eram casados $(68,4 \%)$, seguidos pelos solteiros $(15,4 \%)$, amasiados $(13,1 \%)$ e divorciados $(3,1 \%)$. O número médio de filhos foi de 2,0, valor esse menor ao encontrado por Alves et al. (2002) com 3,2; Silva (1999) com 3,0 e Minetti (1996) com 2,8 . Foi verificado que $65,5 \%$ dos trabalhadores eram possuidores de casa própria.

A média geral de idade dos trabalhadores foi de 32,4 anos, valor próximo ao encontrado por Silva (1999) com 33,8 anos em marcenarias no município de Viçosa, Minas Gerais e superior ao encontrado por Fiedler (1998) com 29 anos para trabalhadores que atuavam na colheita de madeira em empresas no litoral norte do estado da Bahia. A estatura média de $169 \mathrm{~cm}$ e o peso médio de 67,62 kg.

Quanto à escolaridade, apenas $29,8 \%$ dos trabalhadores possuía o ensino fundamental completo, enquanto $15,4 \%$ tinham completado o ensino médio.

Os resultados sobre origem dos trabalhadores evidenciaram que a maioria $(67,3 \%)$ era de origem urbana, indicando que as indústrias absorvem mão-de-obra da própria área urbana.

O percentual de fumantes $(37,5 \%)$ e de consumidores de bebidas alcoólicas $(57,4 \%)$ foi considerado significativo cujos valores foram próximos aos encontrados por Fiedler (1998) para trabalhadores florestais com $37,8 \%$ e $59,8 \%$ respectivamente. Os dados relativos à lateralidade indicaram que $87,4 \%$ eram destros e $12,6 \%$ canhotos.

\section{Condições de trabalho}

As condições de trabalho dos trabalhadores nas indústrias e algumas conseqüencias dessas condições são analisadas a seguir, de acordo com vários itens considerados.

\section{Características gerais de trabalho}

A jornada média de trabalho era de $8 \mathrm{~h} 32 \mathrm{~min}$, de segunda a sexta-feira, perfazendo um total de 42,4 horas semanais. Esses valores estão de acordo com a jornada de trabalho máxima permitida pela Constituição brasileira de 1988 (BRASIL 1988). Questionados em relação à satisfação com o horário de trabalho, a grande maioria dos trabalhadores $(97,0 \%)$ mostraram-se satisfeitos.

Quando os trabalhadores foram questionados a respeito dos motivos que levaram a exercer a função atual na empresa, a maioria $(58,2 \%)$ afirmou ser pela solicitação das indústrias e pela experiência anterior $(22,4 \%)$. Esses resultados evidenciaram a importância de estabelecer melhores critérios no processo de seleção de pessoal por parte das empresas. Tais critérios devem levar em consideração, além da solicitação e interesse do trabalhador, a aplicação de testes de seleção específicos visando à escolha dos mais aptos dentro de cada função.

Quando questionados quanto à satisfação com a empresa, 83,6\% dos trabalhadores afirmaram satisfeitos, ao passo que 79,1\% mostraram-se satisfeitos com função que exercem, por gostarem e por estarem acostumados com o trabalho. Todavia, 37,3\% dos trabalhadores afirmaram que gostariam de mudar de atividade cujo principal motivo era a chances da obtenção de melhores salários (14,9\%).

Para $20,9 \%$ dos entrevistados, o trabalho foi considerado pesado, enquanto que para $22,4 \%$ moderadamente pesado, $55,2 \%$ leve e $1,5 \%$ muito leve.

Questionados sobre quem controla o ritmo de trabalho, a maioria dos trabalhadores (68,7\%) afirmou que eram eles próprios, sendo feito de acordo com a produção exigida para 52,2\% e com a velocidade da máquina para $14,9 \%$. Esse resultado demonstra que, possivelmente, as máquinas utilizadas no trabalho não influenciam no ritmo dos trabalhadores.

\section{Saúde}

A maioria dos entrevistados $(82,1 \%)$ afirmou nunca ter tido problemas de saúde originado do trabalho que executam atualmente. O percentual médio de trabalhadores atingidos por problemas de lombalgia foi de $31,3 \%$, os quais ocorreram na maioria dos casos durante a jornada de trabalho. Tais problemas foram citados em virtude da própria característica do trabalho na qual, em alguns casos, ocorrem o levantamento de peso em excesso e a adoção de posturas inadequadas.

A média de horas de sono foi de 7 h50min. A grande maioria $(86,6 \%)$ afirmou ser esse período

Ciência Florestal, v. 13, n. 2, 2003 
suficiente. Todavia, 34,3\% disseram sentir cansaço ao iniciar a jornada de trabalho, cujos motivos foi a realização de horas-extras e pelo excesso de deslocamentos entre a empresa e as suas residências o qual é realizado de bicicleta e a pé para 62,7 e $37,3 \%$ respectivamente. Isso ocorreu pelo fato da maioria dos trabalhadores terem que almoçar em suas residências, em razão da falta de um local apropriado em todas as empresas para a realização das refeições.

\section{Segurança no trabalho}

No que se refere à segurança no trabalho, 97,0\% dos trabalhadores afirmaram que as empresas fornecem os Equipamentos de Proteção Individual (EPI's) necessários à realização de suas tarefas. Os EPI's utilizados pelos trabalhadores são apresentados na Tabela 2.

Dentre os entrevistados, 94,0\% afirmaram que havia uma reposição adequada dos EPI's; $88,1 \%$ consideraram que os EPI's são suficientes na prevenção de acidentes e 43,3\% afirmaram que eles já os protegeram de algum acidente. Todavia, 46,3\% dos trabalhadores afirmaram que o protetor auricular foi $o$ EPI que mais incomodava na execução do trabalho. As principais causas foram as dores de cabeça e de ouvido causadas pelo protetor auricular, por apertar e esquentar.

TABELA 2: Percentual de trabalhadores que usavam os EPI's no trabalho.

TABLES 2: Percentual of workers that used EPI's in the work.

\begin{tabular}{|c|c|}
\hline EPI's & Percentual (\%) \\
\hline Botas & 100,0 \\
\hline Protetor auricular & 98,5 \\
\hline Luvas & 50,7 \\
\hline Avental & 26,9 \\
\hline Máscara & 5,9 \\
\hline Protetor facial & 4,5 \\
\hline Capa de chuva & 1,5 \\
\hline
\end{tabular}

Foi verificado que $43,3 \%$ dos trabalhadores já sofreram algum tipo de acidente durante o trabalho na empresa, tendo as mãos, sido a parte mais atingida (67,7\%). No momento do acidente, 65,5\% dos trabalhadores afirmaram estar usando os EPI's necessários à execução de seu trabalho. Na maioria dos acidentes (96,5\%), houve perda de tempo no trabalho, acima de 15 dias para 43,3\% dos acidentados e de 5 a 15 dias para 26,7\% dos acidentados. A maioria dos trabalhadores afirmou que as principais causas dos acidentes foram a falta de atenção no trabalho $(40,0 \%)$ e pelos problemas de funcionamento das máquinas $(23,3 \%)$.

Para 54,7\% dos trabalhadores, existem atividades ou situações de trabalho que oferecem maior risco de acidentes cujas principais causas foram a possibilidade de rompimento da serra de fita e queda de toras das pilhas o que é confirmado quando os trabalhadores foram questionados sobre as máquinas mais perigosas, em que $45,0 \%$ afirmou ser a serra de fita, sendo ainda citados a destopadeira, tupia e plaina.

Todas as empresas estudadas ofereciam serviços de primeiros-socorros, porém somente $76,1 \%$ dos trabalhadores afirmaram conhecer a existências desses serviços.

\section{Treinamento}

Dos trabalhadores entrevistados, a maioria $74,6 \%$ não recebeu treinamento para exercer a função, cujo processo de aprendizagem ocorreu nas próprias empresas. Dentre os $25,4 \%$ de trabalhadores que receberam treinamento, $16,4 \%$ considerou o treinamento suficiente, enquanto $14,9 \%$ tiveram dificuldades de assimilação do conteúdo. O período do treinamento variou de um dia a quatro meses, conforme a função. A maioria $(64,2 \%)$ afirmou sobre a necessidade de treinamentos específicos para a realização das tarefas bem como de reciclagens periódicas.

Somente $31,3 \%$ dos trabalhadores estavam aptos para a realização de manutenções nas máquinas, dos quais apenas $8,9 \%$ receberam treinamento para tal função. Esses resultados mostram a importância da oferta de treinamento aos operadores de máquinas. O treinamento deverá abordar não somente sobre as técnicas de operação e segurança das máquinas, mas também sobre manutenção. 


\section{Alimentação}

Do total de trabalhadores entrevistados, $95,5 \%$ relataram fazer regularmente as três principais refeições diárias, café-da-manhã, almoço e jantar; devendo ressaltar que 92,5\% tomavam café da manhã; $28,4 \%$ tomavam um lanche no período da tarde e 13,4\% tomavam um lanche noturno, sendo apenas esse último fornecido pelas empresas, quando da realização de horas extras.

Dentre os entrevistados, $77,6 \%$ almoçavam em suas residências pela falta de local apropriado na empresa. 91,0 dos entrevistados consideravam que as refeições eram de qualidade, enquanto e $86,6 \%$ relataram que as refeições eram suficientes em termos de quantidade para a reposição das energias consumidas durante o dia de trabalho.

Com relação ao consumo de água de cada trabalhador durante a jornada de trabalho, a média foi de 1,5 litros/dia, valor esse abaixo do recomendado pela Norma Regulamentadora NR-24, que é de 2,0 litros/dia. A água era consumida de torneiras e bebedouros para $74,6 \%$ e $25,4 \%$ dos trabalhadores respectivamente.

Tais resultados mostraram que as empresas necessitam tomar providências com relação à alimentação dos trabalhadores. Uma delas é o fornecimento de lanche no período diurno; instalação de bebedouros de água com temperatura e em local adequado e melhorias ou instalação de locais adequados para a realização das refeições.

\section{Opinião dos operadores a respeito das máquinas}

A maioria dos operadores $(91,7 \%)$ afirmou que as máquinas utilizadas por eles oferecem segurança satisfatória, sendo que para 54,2\%, as máquinas encontram-se em perfeitas condições de operação.

Em relação do posto de trabalho, $80,6 \%$ dos entrevistados afirmou que o posicionamento e a distribuição espacial das máquinas dentro das indústrias não comprometem a segurança e a produtividade do trabalho. Para 90,4\% dos operadores, os controles das máquinas são fáceis de operar, enquanto $87,8 \%$ afirmaram que os controles estão dentro da zona de alcance normal dos movimentos, não exigindo grandes esforços físicos e mantendo-os em uma postura adequada. Apenas 8,2\% relataram que as controles das máquinas não são indicados claramente, sendo de difícil compreensão.

De acordo com a análise subjetiva dos operadores, 15,0\% dos entrevistados consideravam a vibração das máquinas excessiva e afirmaram que esta prejudicava a execução do trabalho.

Quando os operadores foram questionados sobre a existência de gases, fuligens e poeiras no ambiente de trabalho, 70,2\% relataram que o maior problema é a presença de finos oriundos, sobretudo do processamento mecânico secundário da madeira, causando tosses, alergias, dores de cabeça e irritações nos olhos. Tais problemas podem ser solucionados com a instalação e/ou melhorias nos sistemas de exaustão existentes nas indústrias. Outro problema relatado pelos operadores foi o forte odor proveniente do setor de pintura o qual é expandido para outros ambientes da empresa.

\section{CONCLUSÕES}

De acordo com os resultados obtidos, pode-se chegar às seguintes conclusões:

\section{Fatores humanos}

Os trabalhadores das indústrias de processamento de madeira tinham um longo tempo de trabalho na empresa, demonstrando a existência de uma baixa rotatividade.

Os trabalhadores apresentaram um perfil de pessoa jovem, de origem urbana, casados e com poucos filhos, possuidores de casa própria e com predominância da lateralidade destra.

O percentual de fumantes $(37,5 \%)$ e de consumidores de bebidas alcoólicas $(57,4 \%)$ foi significativo, podendo afetar a saúde dos trabalhadores.

\section{Condições de trabalho}

\section{Características gerais de trabalho}

A solicitação da empresa e a experiência na função foram os principais motivos que levaram os trabalhadores a exercer as funções na empresa, evidenciando sobre a necessidade do estabelecimento de 
melhores critérios no processo de seleção de pessoal.

Foi verificado uma alta incidência de pessoas com vontade de mudar de atividade cujo principal motivo era a chance da obtenção de melhores salários.

Saúde

As maiores reclamações sobre dores no corpo foram relativas às lombalgias $(31,3 \%)$, por causa do levantamento de peso em excesso e a adoção de posturas inadequadas.

Uma grande fração dos trabalhadores relatou sentir cansaço ao iniciar a jornada de trabalho, pela realização de horas extras e excesso de deslocamentos entre a empresa e suas residências.

\section{Segurança}

A média de trabalhadores que sofreram acidentes foi alta $(43,3 \%)$, sendo as mãos a parte do corpo mais atingida.

Para 54,7\% dos trabalhadores, o rompimento da serra de fita e a queda de toras das pilhas são as situações do trabalho que mais causam risco de acidentes.

\section{Treinamento}

O nível de treinamento era baixo $(25,4 \%)$, havendo manifestações a favor de treinamentos constantes.

Apenas $31,3 \%$ dos operadores estavam aptos para realização de manutenções, em que apenas $8,9 \%$ receberam treinamento, evidenciando a necessidade de oferta de treinamentos para essa função.

\section{Alimentação}

A maioria dos entrevistados $(77,6 \%)$ almoçava em suas residências, pela falta de local apropriado nas empresas.

O consumo de água durante a jornada de trabalho foi em média de 1,5 litros/dia, valor este abaixo do recomendado pela Norma Regulamentadora NR-24, que é de 2,0 litros/dia.

\section{Opinião dos operadores a respeito das máquinas}

A maioria dos operadores relataram que as máquinas utilizadas por eles oferecem segurança satisfatória e estão distribuídas adequadamente dentro da indústria.

Uma grande fração dos trabalhadores relatou sobre a existência de poeiras e fuligens no ambiente de trabalho, causando tosses, alergias, dores de cabeça e irritações nos olhos.

\section{REFERÊNCIAS BIBLIOGRÁFICAS}

ALVES, J. U.; MINETTI, L. J.; SOUZA, A. P.; GOMES, J. M. Avaliação dos fatores humanos e das condições de trabalho em viveiros florestais. Revista Árvore, v. 26, n. 1, p. 127-133, 2002.

BRASIL. Constituição da República Federativa do Brasil. Brasília: Senado Federal, 1988. 193 p.

FIEDLER, N. C. Análise de posturas e esforços despendidos em operações de colheita florestal no Litoral Norte do Estado da Bahia. 1998. 103p. Tese (Doutorado em Ciência Florestal) - Universidade Federal de Viçosa, Viçosa, 1998.

GRANDJEAN, E. Fitting the task to the man: an ergonomic approach. London: Taylor e Francis, 1982. 379 p.

IIDA, I. Ergonomia: projeto e produção. São Paulo: Edgard Blucher, 1990. 465 p.

MINETTI, L. J. Análise de fatores operacionais e ergonômicos na operação de corte florestal com motosserra . 1996. 211p. Tese (Doutorado em Ciência Florestal) - Universidade Federal de Viçosa, Viçosa, 1996.

SILVA, K. R. Análise de fatores ergonômicos em marcenarias no município de Viçosa, MG. 1999. 96 p. Dissertação (Mestrado em Ciência Florestal) - Universidade Federal de Viçosa, Viçosa, 1999. 